\title{
DISEASE PROFILE AND SOCIO-ECONOMIC STATUS OF PATIENTS ATTENDING AT ENDOCRINE OUTPATIENT DEPARTMENT OF A TERTIARY LEVEL HOSPITAL
}

\author{
MD. ABDUL MANNAN ${ }^{1}$, KAZI JAHANGIR HOSSAIN ${ }^{2}$, MD. MUSTAFA KAMAL ${ }^{3}$
}

\begin{abstract}
The aim of this study was to find out the pattern of endocrine diseases and socioeconomic status of the patients attending at outpatient department of endocrinology of Sir Salimullah Medical College Mitford Hospital, Dhaka. A total of 498 endocrine patients were selected on the basis of defined criteria from September 2007 to August 2008. Of the 498 patients, 292 were female and 206 male. Majority of female patients were housewives (86.3\%) while most of the male patients were businessmen (86.4\%). Majority of them (59.4\%) were in the age range of $41-75$ years and 92.0\% were married. About 7\% were found obese, comparatively more in male patients. In endocrine disease pattern, $36.9 \%$ had diabetes mellitus, $18 \%$ hypothyroidism and $6.0 \%$ goiter. Impaired glucose tolerance (IGT), hyperthyroidism, hirsutism, gynaecomastia, infertility, gestational diabetes mellitus (GDM), hyperprolactinemia and short stature were found in $2.0 \%$, $1.6 \%, 1.6 \%, 1.2 \%, 0.8 \%, 0.8 \%, 0.4 \%$ and $0.4 \%$ respectively. About $30.0 \%$ of the endocrine patients were found to be associated with other non-endocrine diseases or obesity. Appropriate medical treatment facilities in combination with motivational enhancement therapies are needed to ensure proper medical management of these patients.
\end{abstract}

Keywords: Endocrine disease, endocrine system disease, socioeconomic status.

\section{Introduction}

Endocrine diseases have a wide range of manifestations affecting many organs and/or systems of the human body. Hormonal diseases such as diabetes mellitus, hypo/hyperthyroidisms, hirsutism, and gynaecomastia are important health hazards all over the world. ${ }^{1}$ Endocrine dysfunctions are a risk factor to many major non-communicable diseases like ischemic heart disease, stroke, chronic renal failure etc. Etiology of hormonal dysfunctions is still not clearly established, but there are some crucial factors. ${ }^{2}$ The important factors are genetic transmission, age and environmental issues such as dietary intake, physical activity, personal habit (tobacco use), and use of steroids etc. Medical management of endocrine diseases can tailor sufferings of the patients significantly, learn to control their crisis and be trained to maintain their normal activities. ${ }^{3}$ Scientific information about endocrine disease related difficulties, physical activities and dietary intake, and personal lifestyle are of vital importance for individuals living with hormonal diseases.
Majority of the hormonal dysfunctions are underdiagnosed in Bangladesh. Facilities for diagnosis and management are still inadequate at all level of the public healthcare services. ${ }^{4}$ Moreover, illiteracy, poor education, inadequate health care facilities, lack of women empowerment, and referral system are inescapable shortcomings in this country. The rapid unplanned urbanization is recognized as one of the important environmental hazards in this country. The trend of diabetes mellitus is higher in urban population in Bangladesh. ${ }^{5-9}$ The environmental factors such as social class, obesity, dietary habit, physical activities etc are significantly influencing these increasing trends. ${ }^{5}$ In recent years, diabetes mellitus and other endocrine diseases such as hypo/hyperthyroidism, goiters, hirsutism, gynaecomastia etc are frequently encountered by the clinicians and it is increasing with time. ${ }^{10-12}$ Therefore, the aim of this study was to investigate pattern of endocrine diseases and socioeconomic-family profile attending at the outpatient department of endocrinology of Sir Salimullah Medical College Mitford Hospital, Dhaka.

1. Professor and Head, Department of Endocrinology, Dhaka Medical College Hospital

2. Assistant Professor, Department of Health Education, National Institute of Preventive and Social Medicine, Mohakhali, Dhaka

3. Assistant Professor, Department of Nutrition and Biochemistry, National Institute of Preventive and Social Medicine, Mohakhali, Dhaka

Correspondence: Prof. Md. Abdul Mannan, Professor and Head, Department of Endocrinology, Dhaka Medical College Hospital, Dhaka 


\section{Materials and Methods}

The studied populations were patients attending at outpatient department of endocrinology and few were referred patients from other departments of Sir Salimullah Medical College Mitford Hospital, Dhaka from September 2007 to August 2008. A total of 498 patients were included in this study. They were selected consecutively on the basis of defined criteria that includes clinical manifestation of hormonal dysfunctions, irrespective of age and gender, not suffering from co-morbid mental disorders or use illicit drugs. A questionnaire was designed to include general information, socioeconomic profile and anthropometrical measurements. The socioeconomic profiles included education, occupation, age, gender and marital status, and family members. The anthropometrical measurements were height, weight and body mass index (BMI). Only positive respondents were selected as research participants consistent with the selection criteria. A written informed consent was taken from each of the selected patients. Diagnosis of an endocrine disease was made following the standard diagnostic criteria. Venous blood from each of the participants was collected for necessary biochemical investigations to confirm diagnosis. The procedures followed for this study were in accordance with the CIOMS guidelines as updated in $2002 .{ }^{13}$

For the diagnosis of diabetes mellitus, impaired glucose tolerance, gestational diabetes mellitus (fasting blood glucose at least 10-14 hours fasting after taking a normal meal); hypothyroidism or hyperthyroidism $\left(\mathrm{T}_{3}, \mathrm{~T}_{4}\right.$, TSH); gynaecomastia (estrogen, prolactin, $\mathrm{FT}_{4}, \mathrm{TSH}$ ) and hirsutism (testosterone, prolactin, TSH) appropriate biochemical and hormonal analysis were performed by standard methods. Biochemical analyses and hormonal assays were carried out by auto analyzer (RA-50, Ireland) and ELISA (enzyme linked immunosorbent assay) method respectively. Standard commercial kits were used in all analyses.SPSS (version 12.0) was used to analyse the data. Descriptive statistics was used for all variables. Values were expressed as percentage.

\section{Results}

Socioeconomic profile and body mass index of the endocrine patients are summarized in the Table I. Of the 498 patients, $58.6 \%$ (292) were female and $41.4 \%$ (206) male. Majority of the patients 59.4\% (296) were in age range of 41-75 years. Of all patients 92.0\% (458) were married and 8.0\% (40) unmarried. Nearly 7\% (37) of the studied population were found obese, comparatively more in male patients.
Table I

Socioeconomic status and Body Mass Index of the endocrine patients $(n=498)$

\begin{tabular}{|c|c|c|c|}
\hline Description & $\begin{array}{c}\text { Female } \\
(\mathrm{n}=292) \\
\%(\mathrm{n})\end{array}$ & $\begin{array}{c}\text { Male } \\
(\mathrm{n}=206) \\
\%(\mathrm{n})\end{array}$ & $\begin{array}{c}\text { Total } \\
(\mathrm{n}=498) \\
\%(\mathrm{n})\end{array}$ \\
\hline Gender & $58.6(292)$ & $41.4(206)$ & $100.0(498)$ \\
\hline \multicolumn{4}{|l|}{ Education } \\
\hline Illiterate & $15.1(44)$ & $19.4(40)$ & $16.9(84)$ \\
\hline 1-9 Class & $34.6(101)$ & $25.2(52)$ & $30.7(153)$ \\
\hline $\mathrm{SSC}$ & $24.3(71)$ & $25.2(52)$ & $24.7(123)$ \\
\hline HSC & $19.2(56)$ & $20.5(42)$ & $19.7(98)$ \\
\hline Degree \& above & $6.8(20)$ & $9.7(20)$ & $8.0(40)$ \\
\hline \multicolumn{4}{|l|}{ Occupation } \\
\hline Housewife & $86.3(252)$ & Nil & $50.6(252)$ \\
\hline Business & $0.7(2)$ & $86.4(178)$ & $36.1(180)$ \\
\hline Others $^{1}$ & $13.0(38)$ & $13.6(28)$ & $13.3(66)$ \\
\hline \multicolumn{4}{|l|}{ Age in year } \\
\hline 14- 30 & $26.7(78)$ & $12.6(26)$ & $20.9(104)$ \\
\hline $31-40$ & $20.5(60)$ & $18.4(38)$ & $19.7(98)$ \\
\hline 41- 50 & $33.6(98)$ & $31.1(64)$ & $32.5(162)$ \\
\hline 51- 60 & $11.7(34)$ & $28.1(58)$ & $18.5(92)$ \\
\hline$>60$ & $7.5(22)$ & $9.8(20)$ & $8.4(42)$ \\
\hline \multicolumn{4}{|l|}{ Marital status } \\
\hline Married & $89.0(260)$ & 96.1(198) & $92.0(458)$ \\
\hline Unmarried & $11.0(32)$ & $3.9(8)$ & $8.0(40)$ \\
\hline \multicolumn{4}{|l|}{ Body Mass Index (BMI) } \\
\hline 14.1 - 18.4 (Under) & $0.7(2)$ & $1.0(2)$ & $0.8(4)$ \\
\hline $18.5-25.0$ (Normal) & $94.2(275)$ & $88.3(182)$ & $91.8(457)$ \\
\hline $25.1-34-4$ (Obese) & $5.1(15)$ & $10.7(22)$ & $7.4(37)$ \\
\hline
\end{tabular}

${ }^{1}$ Others: Teacher, Service holders, Students

In 498 patients, $36.9 \%$ (184) had been suffering from diabetes mellitus (DM). It had relatively higher prevalence among the male patients (Table II). Nearly $18.0 \%$ (90) of them were found to be suffering from hypothyroidism, more in female. $6.0 \%$ (30) had goiter, more common in female. IGT, hyperthyroidism, hirsutism, gynaecomastia, infertility, GDM, hyperprolactemia and short stature were also diagnosed in $2.0 \%(10), 1.6 \%$ (8), $1.6 \%$ (8), $1.2 \%(6), 0.8 \%(4), 0.8 \%(4), 0.4 \%(2)$ and $0.4 \%(2)$ among them respectively. About $30.0 \%$ (150) of the patients had been suffering from endocrine diseases with other non endocrine diseases or complications. Among them, $17.1 \%(\mathrm{n}=85)$ were diabetes mellitus with hypertension in equal prevalence in both men and women patients respectively. Endocrine disease profile among the studied population is described in detail in the Table II. 
Table II

Disease profile of the endocrine patients $(n=498)$

\begin{tabular}{llccc}
\hline & Name of Disease & Female (n=292) & Male(n=206) & Total(n=498) \\
& & $\%(\mathrm{n})$ & $\%(\mathrm{n})$ & $36.9(184)$ \\
\hline 1 & Diabetes Mellitus (DM) & $31.5(92)$ & $44.7(92)$ & $18.2(90)$ \\
2 & Hypothyroidism & $23.2(68)$ & $10.7(22)$ & $6.0(30)$ \\
3 & Goiter & $8.2(24)$ & $2.9(6)$ & $2.0(10)$ \\
4 & Impaired glucose tolerance (IGT) & $2.7(8)$ & $1.0(2)$ & $1.6(8)$ \\
5 & Hyperthyroidism & $2.1(6)$ & $1.0(2)$ & $1.6(8)$ \\
6 & Hirsutism & $2.7(8)$ & Nil & $1.2(6)$ \\
7 & Gynaecomastia & Nil & $2.9(6)$ & $0.8(4)$ \\
8 & Infertility & $1.4(4)$ & $\mathrm{Nil}$ & $0.8(4)$ \\
9 & Gestational Diabetes Mellitus & $1.4(4)$ & $\mathrm{Nil}$ & $0.4(2)$ \\
10 & Hyperprolactemia & $0.7(2)$ & $\mathrm{Nil}$ & $0.4(2)$ \\
11 & Short stature + Obesity & $\mathrm{Nil}$ & $1.0(2)$ & $17.1(85)$ \\
12 & DM + Hypertension (HTN) & $17.5(51)$ & $16.5(34)$ & $3.0(15)$ \\
13 & DM + HTN + Obesity & $2.4(7)$ & $3.9(8)$ & $2.8(14)$ \\
14 & DM + Obesity & $0.7(2)$ & $5.8(12)$ & $2.8(14)$ \\
15 & DM + Peripheral Vascular Disease & $0.7(2)$ & $5.8(12)$ & $2.4(12)$ \\
16 & DM + Ischemic heart disease & $2.7(8)$ & $1.9(4)$ & $0.8(4)$ \\
17 & DM + Hypothyroidism & Nil & $1.9(4)$ & $0.8(4)$ \\
18 & IGT + HTN + Obesity & $1.4(4)$ & $\mathrm{Nil}$ & $0.4(2)$ \\
19 & Hypothyroidism + Obesity & $0.7(2)$ & $\mathrm{Nil}$ & \\
\hline
\end{tabular}

\section{Discussion}

Diabetes mellitus and thyroid disease are the most common endocrine diseases in all the nations of the world. ${ }^{1}$ People living with endocrine diseases are often the victim of social stigmatisms. The endocrine diseases such as goiter, hirsutism, gynaecomastia, short stature, infertility etc and social stigmatisms critically affect physical, mental and social health of the patients. Department of endocrinology in medical college hospitals presents an opportunity to study different kind of endocrine diseases in a semicontrolled environment. There are many shortcomings e.g. compliance with endocrine disease treatment protocol is often absent in the medical college hospitals. It is well established that scientific evaluation and enlightened attitudes towards endocrine diseases may abolish the forcible incarceration of the patients from pejorative languages and social stigmatisms. ${ }^{14}$

Only $8.0 \%$ of the endocrine patients were found to be graduates and $75 \%$ of them had basic education (primary to higher secondary level). Most of the female patients were housewives. Patriarchal society, religious belief, social stigmatisms as well as socio-cultural environment may be the important contributing factors for such type of socioeconomic characteristics of the women in Bangladesh. Majority of the endocrine patients were married and their social background as well as other socioeconomic profile are consistent with the reported national statistical data. ${ }^{15}$ A striking finding of this study was that about $7.5 \%$ of the studied endocrine patients had obesity which is alarming signals to the nation for the epidemic of major non-communicable diseases such as ischemic heart disease, stroke, renal failure, and hypertension etc. Similar socioeconomic characteristics were also found in other studies. ${ }^{10-11}$

In this study, it was found that majority of the attending patients were diagnosed as diabetes mellitus followed by hypothyroidism and goiter (Table II). Moreover, IGT, hyperthyroidism, hirsutism, 
gynaecomastia, infertility, GDM, hyperprolactinemia and short stature were also diagnosed in significant number of the patients. The studied endocrine disease profile indicated the necessity for treatment facility in at least secondary level of government health sector. The patients seek appropriate treatment from public hospitals due to financial limitations. Similar distributions of endocrine diseases were also found in other studies. ${ }^{5,8}$ Appropriate medical treatment facilities in combination with motivational enhancement therapies in public health sectors may need to ensure for medical management of the endocrine patients in Bangladesh.

\section{Acknowledgement}

Authors thank to the Director of Sir Salimullah Medical College Mitford Hospital, Dhaka for his kind assistance. Authors also thank to the technical staffs of the hospital for their cooperation.

\section{References}

1. Strachan MWJ, Walker BR. Endocrine disease. In: Davidson's Principle and Practice of Medicine. Boon NA, Colledge NR, Walker BR, Hunter JAA, eds, $20^{\text {th }}$ edition. Philadelphia: Elsevier Science, 2006: 73999.

2. Frier BM, Fisher M. Diabetics Mellitus. In: In: Davidson's Principle and Practice of Medicine. Boon NA, Colledge NR, Walker BR, Hunter JAA, eds, $20^{\text {th }}$ edition. Philadelphia: Elsevier Science, 2006: 80548.

3. American Diabetes Association. Gestational diabetes mellitus. Diabetes care 2001; 24: S77-S79.

4. Strategic plan for surveillance and prevalence of non-communicable diseases in Bangladesh 200720010. Director General of Health Services (DGHS), Ministry of Health and Family Welfare, with technical assistance from WHO 2007.

5. Sayeed MA, Mahtab H, Khanam PA, et al. Prevalence of diabetes mellitus and impaired fasting glucose in urban population of Bangladesh. Bang Med Resh Coun Bull 2007; 33(1): 1-12.

6. Gupta A, Gupta R, Sarna M, et al . Prevalence of diabetes, impaired fasting glucose and insulin resistance syndrome in an urban Indian population. Diabetes Res Clin Pract 2003; 61: 69-76.

7. Gu D, Reynolds K, Duan X, et al. Inter Asia Collaborative Group. Prevalence of diabetes and impaired fasting glucose in Chinese adult population. Diabetologica 2003; 46: 1190-98.

8. The Inter Asia Collaborative Group. Cardiovascular risk factor levels in urban and rural Thailand - The international collaborative study of cardiovascular disease in Asia (inter Asia). J Cardiovasc Risk 2003; 10: 249-57.

9. Ramachandran A, Snehalatha C, Latha E, et al. Rising prevalence of NIDDM in an urban population in India. Diabetologica 1997; 40: 232-37.

10. Afroz F, Nazimuddin K, Sarker RSC, et al. Etiological analysis of hypothyroidism-a study of 133 cases. Bangladesh Journal of Medicine 2008; 19(2): 44-46.

11. Fariduddin M, Majumder MI, Jalil Chowdhury MA, et al. Lipid abnormalities in hypothyroid patients. Bangladesh Journal of Medicine 2009; 20(1): 13-16.

12. Begum M, Shefyetullah KM, Naushaba H, et al. Proportion of glandular tissue and stroma of thyroid gland in differnet age grpoups- a postmertem study. Sir Salimullah Med Coll J 2008; 16(1): 11-13.

13. Council for International Organization of Medical Sciences (CIOMS). Biomedical research ethics: updating international guidelines. New York: CIOMS Publication 2002: 1-89.

14. Oliver HR. Psychiatric aspects of Hansen's disease (leprosy). J Clin Psychiatry 1987; 48: 477-79.

15. Bangladesh Bureau of Statistics. Statistical Yearbook of Bangladesh 2006. Finance, administration and M/S wing, Dhaka 2007: 49-94. 